\title{
Exigência Nutricional de Lisina Digestível para Frangos de Corte ${ }^{1}$ \\ Walter Amaral Barboza², Horacio Santiago Rostagno³, Luiz Fernando Teixeira Albino³, Paulo Borges Rodrigues ${ }^{4}$
}

\begin{abstract}
RESUMO - O objetivo deste trabalho foi determinar, mediante ensaio de digestibilidade, as exigências nutricionais de lisina digestível verdadeira para frangos de corte nas quatro fases de crescimento. Quatro experimentos de desempenho, realizados previamente, permitiram estimar a exigência de lisina total para frangos de corte nas fases de 1 a 21, 15 a 40, 22 a 40 e 42 a 48 dias de idade. Foram utilizados 30 galos, adultos, Leghorn, cecectomizados com peso médio de $2316 \pm 190 \mathrm{~g}$, sendo alojados, individualmente, em gaiolas com bandejas coletoras de excretas, utilizando-se o método de alimentação forçada. O delineamento experimental foi inteiramente casualizado, com cinco tratamentos (quatro com dietas e um em jejum) e seis repetições. Foram utilizadas as dietas basais das quatro fases de crescimento, contendo 1,0;0,825;0,80; e 0,75\% de lisina total. Com base nos coeficientes de digestibilidade determinados de 93,3; 93,58; 89,76; e 92,25\% e considerando a L-lisina HCL suplementada como 100\% digestível, as exigências de lisina digestível verdadeira foram 1,130; 1,075; 0,95; e 0,84\% para as fases de 1 a 21, 15 a 40, 22 a 40 e 42 a 48 dias de idade, respectivamente. Ao aplicar o modelo de regressãolinear, foram obtidas as equações $\hat{Y}(\%$ lisina/Mcal $)=0,4335-0,003284 \mathrm{Xr}^{2} 0,98 \mathrm{e} \hat{\mathrm{Y}}(\%$ lisina/Mcal $)=0,41081-0,003213 \mathrm{X}$, $\mathrm{r}^{2} 0,96$ para lisina total e digestível, respectivamente, sendo $\mathrm{x}$ a idade média das aves, em dias.
\end{abstract}

Palavras-chave: exigência nutricional, frangos de corte, galos, lisina digestível

\section{Nutritional Requirement of Digestible Lysine for Broiler Chickens}

\begin{abstract}
The objective of this work was to determine, through a digestibility assay, the nutritional requirement of true digestible lysine for broiler chickens, in the four growing phases. Four performance experiments, previously performed, allowed the determination of total lysine requirement of broiler chickens in the periods from 1 to 21,15 to 40,22 to 40 and 42 to 48 days of age. Thirty cecectomized adults Leghorn roosters were used, with an average weight of $2316 \pm 190 \mathrm{~g}$, and individually caged in batteries with excreta collecting trays and using the precision feeding method. A completely randomized design was used, with five treatments (four with diets and one fasted) and six replications. The basal diets from the four growing phases, contained 1.0, 0.825, 0.80 and $0.75 \%$ total lysine, were used. Based on the determined digestibility coefficients of $93.3 ; 93.58 ; 89.76$ and $92,25 \%$ and considering the supplemented L-Lysine HCL as 100 $\%$ digestible, the true digestible lysine requirements were: $1.130 \% ; 1.075 \% ; 0,95 \%$ and $0,84 \%$ for $1-21 ; 15-40 ; 22-40$ and $42-48$ days of age, respectively. Using the linear regression model, the obtained equations were $\hat{Y}$ (\%total lysine/Mcal) $=0.4335-0,003284 X \mathrm{R}^{2}$ 0.98 and $\hat{\mathrm{Y}}(\%$ digestible lysine/Mcal $)=0,41081-0,003213 \mathrm{X}, \mathrm{R}^{2} 0.96$ for total and digestible lysine, respectively, where $\mathrm{x}$ was the average birds age in days.
\end{abstract}

Key Words: broiler, digestible lysine, nutritional requirement, rooster

\section{Introdução}

A exigência nutricional de lisina total para frangos de corte tem sido estudada por diferentes autores (SURISDIARTO e FARRELL, 1991; WALDROUP, 1993; e BILGILI et al., 1992). Contudo, considerando as variações na digestibilidade dos aminoácidos nos diferentes alimentos utilizados na alimentação das aves, torna-se necessário estabelecer as exigências nutricionais com base nos aminoácidos digestíveis.

Trabalhando com frangos de corte na fase de 8 a 21 dias de idade, HAN e BAKER (1991) estimaram a exigência de 1,01 e $1,21 \%$ de lisina digestível ou $1,17 \%$ e $1,41 \%$ de lisina total para máximo ganho de peso e conversão alimentar, respectivamente. Em estudo subseqüente, HAN e BAKER (1992) confirmaram estes resultados, não encontrando diferenças nas exigências entre machos e fêmeas. Já HAN e BAKER (1994), trabalhando com frangos de corte na fase de 22 a 42 dias, estimaram exigência de 0,85 e $0,89 \%$ de lisina digestível para máximo ganho de peso e conversão alimentar, respectivamente.

Considerando que, no Brasil, são escassos os trabalhos avaliando as exigências das aves em

\footnotetext{
1 Parte da tese apresentada à Universidade Federal de Viçosa para a obtenção do título de "Doctor Science".

2 Professor do Departamento de Zootecnia da UFRPE - Recife, PE.

3 Professor do Departamento de Zootecnia da UFV - Viçosa, MG

4 Professor do Departamento de Zootecnia da UFLA - Lavras, MG.
} 
BARBOZA et al.

aminoácidos digestíveis, conduziu-se este trabalho com os objetivos de avaliar os níveis de lisina digestível para frangos de corte nas diferentes fases de criação e calcular uma curva de predição de lisina digestível, em função da idade das aves.

\section{Material e Métodos}

O experimento foi conduzido no setor de Avicultura do Departamento de Zootecnia, do Centro de Ciências Agrárias da Universidade Federal de Viçosa.

Foram utilizados 30 galos adultos, submetidos ao método de alimentação forçada, conhecido como método de alimentação precisa (SIBBALD, 1976). O delineamento experimental foi inteiramente casualizado, com cinco tratamentos (quatro dietas basais e um jejum), seis repetições por tratamento e um galo por unidade experimental. As dietas basais 1, 2, 3 e 4 foram formuladas para atender as exigências nutricionais dos frangos de corte para as fases de 1 a 21; 15 a 40; 22 a 40; e 42 a 48 dias de idade respectivamente, segundo ROSTAGNO et al. (1983), exceto para lisina (Tabela 1).

Os resultados obtidos dos galos em jejum foram utilizados para realizar as correções correspondentes às excreções endógenas e metabólicas. Na Tabela 2 , estão representados os valores analisados de proteína bruta e aminoácidos totais das dietas basais.

Os galos adultos Leghorne cecectomizados, pesando em média $2316 \pm 190 \mathrm{~g}$, foram alojados em gaiolas individuais no laboratório de animais do Departamento de Zootecnia, à temperatura média de $23,2^{\circ} \mathrm{C}$. Os mesmos foram mantidos em jejum por um período de 24 horas, para que seus tratos digestivos

Tabela 1 - Composição porcentual das dietas basais nas diferentes fases experimentais Table 1 - Percentage composition of the basal diet in the experimental phases

\begin{tabular}{|c|c|c|c|c|}
\hline $\begin{array}{l}\text { Ingrediente } \\
\text { (Ingredient }\end{array}$ & $\begin{array}{c}\text { Dieta } 1 \\
\text { Diet } 1\end{array}$ & $\begin{array}{l}\text { Dieta } 2 \\
\text { Diet } 2\end{array}$ & $\begin{array}{c}\text { Dieta } 3 \\
\text { Diet } 3\end{array}$ & $\begin{array}{c}\text { Dieta } 4 \\
\text { Diet } 4\end{array}$ \\
\hline Milho (Corn) & 44,216 & 51,472 & 52,548 & 53,598 \\
\hline Sorgo (Sorghum) & 15,000 & 15,000 & 15,000 & 15,000 \\
\hline Farelo de soja, $46 \%$ (Soybean meal, $46 \%$ ) & 27,760 & 19,046 & 19,901 & 18,620 \\
\hline Farelo de glúten de milho (Corn gluten meal) & 7,009 & 6,000 & 7,649 & 6,000 \\
\hline Óleo de soja (Soybean oil) & 1,755 & 2,450 & 0,869 & 2,480 \\
\hline Fosfato bicálcico (Dicalcium phosphate) & 1,837 & 0,400 & 1,707 & 1,640 \\
\hline Farinha de carne e ossos (Bone and meat meal) & - & 3,446 & - & - \\
\hline Calcário(Limestone) & 1,195 & 0,565 & 1,110 & 1,137 \\
\hline $\operatorname{Sal}($ Salt $)$ & 0,300 & 0,260 & 0,300 & 0,300 \\
\hline L-Treonina (L-Threonine) & - & 0,044 & - & - \\
\hline L-Triptofano (L-Triptophan) & - & 0,013 & - & - \\
\hline DL-Metionina (DL-Methionine) $99 \%$ & 0,158 & 0,234 & 0,146 & 0,133 \\
\hline Ácido propiônico (Propionic acid) & - & 0,300 & - & - \\
\hline Amido (Starch) & 0,400 & 0,400 & 0,400 & 0,400 \\
\hline Premix mineral $^{2}$ (Mineral premix) & 0,050 & 0,050 & 0,050 & 0,050 \\
\hline Premix vitamínico ${ }^{3}$ (Vitamin premix) & 0,100 & 0,100 & 0,100 & 0,100 \\
\hline Bacitracina de zinco (Zinc bacitracin) $10 \%$ & 0,050 & 0,050 & 0,050 & 0,050 \\
\hline Coccidiostático (Coccidiostatic) ${ }^{4}$ & 0,100 & 0,100 & 0,100 & 0,100 \\
\hline Cloreto de colina (Choline chloride) $60 \%$ & 0,100 & 0,100 & 0,100 & 0,100 \\
\hline Antioxidante $(\text { Antioxidant })^{5}$ & 0,050 & 0,050 & 0,050 & 0,050 \\
\hline \multicolumn{5}{|l|}{$\begin{array}{l}\text { Composição calculada } \\
\text { Calculated composition }\end{array}$} \\
\hline$\overline{\mathrm{EM}}(M E), \mathrm{kcal} / \mathrm{kg}$ & 3050 & 3200 & 3100 & 3200 \\
\hline Proteína bruta (Crude protein), \% & 22,00 & 19,60 & 19,50 & 18,00 \\
\hline Cálcio (Calcium), \% & 1,00 & 0,90 & 0,91 & 0,90 \\
\hline P disponível (Available phosphorus), \% & 0,45 & 0,41 & 0,42 & 0,41 \\
\hline Metionina + cistina (Methionine + cystine), $\%$ & 0,92 & 0,90 & 0,85 & 0,78 \\
\hline Lisina (Lysine), \% & 1,00 & 0,83 & 0,80 & 0,75 \\
\hline
\end{tabular}

${ }^{1}$ Dieta 1 = 1 a 21 dias; Dieta $2=15$ a 40 dias; Dieta $3=22$ a 40 dias e Dieta $4=42$ a 48 dias de idade.

1 Diet $1=1$ to 21 days; Diet $2=15$ to 40 days; Diet $3=22$ to 40 days; Diet $4=42$ to 48 days of age.

2 Aves = Vit. A, 12.000.000 Ul; Vit. D 3 , 2500 UI; Vit. E, 30.000 Ul; Vit. K, 3 g; Vit. B, 2 g; Vit. $B_{2}, 7$ g; Vit. B, 3 g; Pantotenato de cálcio (Calcium pantotenate), $10 \mathrm{~g}$; Ácido nicotínico (Nicotinic acid), $35 \mathrm{~g}$; Vit. $\mathrm{B}_{12}, 0,015 \mathrm{~g}$; Biotina (Biotin), 0,07 g, Ácido fólico (Folic acid), $1 \mathrm{~g}$; Selênio (Selenium), 0,12 g

3 Aves = Ferro (Iron), 100 g; Manganês (Manganese), 160 g; Zinco (Zinc), $100 \mathrm{~g}$; Cobre (Copper), $20 \mathrm{~g}$; Cobalto (Cobalt), 2g, lodo (lodine), $2 \mathrm{~g}$

${ }^{4}$ Coxistac $6 \%$ - Salinomicina sódica. Pfizer

${ }^{5}$ BHT - Butil hidroxi tolueno. 
1100 Rev. bras. zootec.

ficassem vazios e, em seguida, forçados a consumir quantidade de $30 \mathrm{~g}$ de ração, introduzida dentro do papo, por meio de um funil colocado via esôfago, sendo que $15 \mathrm{~g}$ foram fornecidos às $8 \mathrm{~h}$ e o restante, às $16 \mathrm{~h}$, tentando-se, com isso, evitar regurgitação da dieta pelos animais.

A coleta de fezes foi feita às $8 \mathrm{e} 16 \mathrm{~h}$, por meio de bandejas revestidas com sacos plásticos, por um período de 56 horas, após o fornecimento da primeira parcela de ração. O material recolhido diariamente foi armazenado em sacos plásticos, colocados em freezer $\left(-10^{\circ} \mathrm{C}\right)$ para posterior pesagem, descongelamento, homogeneização e liofilização. As amostras liofilizadas foram condicionadas em vidros para futuras análises.

As análises de matéria seca e proteína bruta foram feitas no Laboratório de Nutrição Animal do Departamento de Zootecnia, na Universidade Federal de Viçosa, e as dos aminoácidos das dietas e das excretas, no Laboratório da Degussa AG, na Alemanha.

Conhecendo as quantidades de aminoácidos ingeridos e excretados de cada dieta e utilizando-se da fração endógena obtida com galos em jejum, foi possível determinar o coeficiente de digestibilidade verdadeira de cada aminoácido das dietas experimentais, utilizando-se a fórmula proposta por ROSTAGNO e FEATHERSTON (1977).

Para calcular a exigência de lisina digestível verdadeira, foram utilizados: a) a exigência de lisina total determinada previamente nas diversas fases de crescimento dos frangos de corte; b) os coeficientes de digestibilidade verdadeira das dietas basais, para obter o conteúdo de lisina digestível verdadeira das dietas basais; c) a digestibilidade verdadeira da lisina sintética suplementada, na forma de L-lisina. $\mathrm{HCl}$ 98\% (78,4\% de lisina), às dietas basais até atingir a exigência nutricional, considerada como $100 \%$ digestível, de acordo com resultados de digestibilidade dos aminoácidos sintéticos obtidos por IZQUIERDO et al. (1988).

Após a determinação das exigências nutricionais de lisina total e digestível, para as quatro fases experimentais estudadas, as mesmas foram padronizadas para o nível de $1000 \mathrm{kcal}$ de $\mathrm{EM} / \mathrm{kg}$ de ração e calculada a idade média de cada fase experimental. Os valores obtidos de lisina total e digestível foram submetidos ao modelo de regressão, para a obtenção de equações lineares $\hat{\mathrm{Y}}=\mathrm{a}-\mathrm{bx}$, para cálculo da estimativa de exigência de lisina ( $\hat{Y}$ em \%/Mcal), em função da idade média $(\mathrm{X})$ das aves.
Tabela 2 -Valores analisados de proteína bruta e aminoácidos totais das dietas basais (\%)

Table 2 - Analyzed values of crude protein and total amino acids in the basal diets (\%)

\begin{tabular}{|c|c|c|c|c|}
\hline \multirow[b]{2}{*}{$\begin{array}{l}\text { Nutriente (\%) } \\
\text { Nutrient }\end{array}$} & \multicolumn{4}{|c|}{$\begin{array}{c}\text { Dietas basais } \\
\text { Basal diets }\end{array}$} \\
\hline & 1 & 2 & 3 & 4 \\
\hline Proteína bruta & 22,00 & 19,60 & 19,54 & 18,06 \\
\hline $\begin{array}{l}\text { Crude protein } \\
\text { Lisina } \\
\text { Lysine }\end{array}$ & 1,01 & 0,80 & 0,81 & 0,77 \\
\hline $\begin{array}{l}\text { Metionina } \\
\text { Methionine }\end{array}$ & 0,51 & 0,54 & 0,48 & 0,43 \\
\hline $\begin{array}{l}\text { Cistina } \\
\text { Cystine }\end{array}$ & 0,39 & 0,31 & 0,36 & 0,32 \\
\hline $\begin{array}{l}\mathrm{Met}+\mathrm{Cis} \\
\mathrm{Met}+\text { cys }\end{array}$ & 0,90 & 0,85 & 0,83 & 0,75 \\
\hline $\begin{array}{l}\text { Treonina } \\
\text { Threonine }\end{array}$ & 0,85 & 0,73 & 0,75 & 0,67 \\
\hline $\begin{array}{l}\text { Arginina } \\
\text { Arginine }\end{array}$ & 1,33 & 1,12 & 1,10 & 1,02 \\
\hline $\begin{array}{l}\text { Isoleucina } \\
\text { Isoleucine }\end{array}$ & 0,97 & 0,78 & 0,86 & 0,77 \\
\hline $\begin{array}{l}\text { Leucina } \\
\text { Leucine }\end{array}$ & 2,36 & 2,08 & 2,27 & 2,00 \\
\hline $\begin{array}{l}\text { Valina } \\
\text { Valine }\end{array}$ & 1,08 & 0,91 & 0,96 & 0,87 \\
\hline $\begin{array}{l}\text { Histidina } \\
\text { Histidine }\end{array}$ & 0,55 & 0,49 & 0,50 & 0,45 \\
\hline $\begin{array}{l}\text { Fenilalanina } \\
\text { Phenilalanine }\end{array}$ & 0,96 & 0,98 & 1,09 & 0,99 \\
\hline
\end{tabular}

\section{Resultados e Discussão}

Os coeficientes de digestibilidade verdadeira dos aminoácidos das dietas basais são apresentados na Tabela 3. O menor coeficiente de digestibilidade da lisina $(89,76 \%)$ foi obtido para a dieta da fase de 22 a 40 dias de idade (Dieta 3 ) e o maior $(93,58 \%$ ), para a dieta da fase de 15 a 40 dias de idade (Dieta 2). Este menor coeficiente de digestibilidade da lisina $(89,76 \%)$ ainda foi superior ao obtido por PARSONS (1991) e HAN e BAKER (1994), que relataram coeficientes de digestibilidade da lisina de 88 e $81,2 \%$, respectivamente, para dietas à base de milho, farelo de soja $\mathrm{e}$ farinha de penas.

Na Tabela 4, são apresentados os conteúdos de aminoácidos digestíveis, analisados, das dietas basais. Para a fase de 1 a 21 dias, a exigência foi de 1,191 e $1,198 \%$ de lisina total, correspondendo a $1,111 \mathrm{e}$ $1,118 \%$ de lisina digestível, para máximo ganho de peso de machos e fêmeas, respectivamente, resultando em exigência média de $1,115 \%$ de lisina digestível. Para a conversão alimentar, machos e fêmeas apre- 
BARBOZA et al.

Tabela 3 - Coeficientes de digestibilidade verdadeira dos aminoácidos das dietas basais

Table 3 - True digestibility coefficients of the amino acids in the basal diets

\begin{tabular}{|c|c|c|c|c|}
\hline \multirow[b]{2}{*}{$\begin{array}{l}\text { Nutriente } \\
\text { Nutrient }\end{array}$} & \multicolumn{4}{|c|}{$\begin{array}{l}\text { Dietas } \\
\text { Diets }\end{array}$} \\
\hline & 1 & 2 & 3 & 4 \\
\hline $\begin{array}{l}\text { Lisina } \\
\text { Lysine }\end{array}$ & 93,30 & 93,58 & 89,76 & 92,25 \\
\hline $\begin{array}{l}\text { Metionina } \\
\text { Methionine }\end{array}$ & 93,94 & 91,71 & 93,89 & 94,24 \\
\hline $\begin{array}{l}\text { Cistina } \\
\text { Cystine }\end{array}$ & 83,24 & 97,43 & 74,19 & 90,60 \\
\hline $\begin{array}{l}\text { Met }+ \text { Cis } \\
\text { Met }+ \text { cys }\end{array}$ & 88,78 & 95,11 & 83,89 & 87,12 \\
\hline $\begin{array}{l}\text { Treonina } \\
\text { Threonine }\end{array}$ & 88,87 & 92,96 & 80,78 & 85,25 \\
\hline $\begin{array}{l}\text { Arginina } \\
\text { Arginine }\end{array}$ & 95,06 & 96,56 & 91,74 & 94,45 \\
\hline $\begin{array}{l}\text { Isoleucina } \\
\text { Isoleucine }\end{array}$ & 93,74 & 94,64 & 90,88 & 93,64 \\
\hline $\begin{array}{l}\text { Leucina } \\
\text { Leucine }\end{array}$ & 95,61 & 98,20 & 93,75 & 95,47 \\
\hline $\begin{array}{l}\text { Valina } \\
\text { Valine }\end{array}$ & 92,92 & 96,07 & 88,10 & 92,52 \\
\hline $\begin{array}{l}\text { Histidina } \\
\text { Histidine }\end{array}$ & 94,41 & 96,83 & 92,67 & 93,33 \\
\hline $\begin{array}{l}\text { Fenilalanina } \\
\text { Phenilalanine }\end{array}$ & 93,66 & - & 91,71 & 94,96 \\
\hline
\end{tabular}

Tabela 4 - Valores de aminoácidos digestíveis verdadeiros das dietas basais

Table 4 - Values of true digestible amino acids in the basal diets

\begin{tabular}{|c|c|c|c|c|}
\hline \multirow{2}{*}{$\begin{array}{l}\text { Nutriente }(\%) \\
\text { Nutrient }\end{array}$} & \multicolumn{4}{|c|}{$\begin{array}{c}\text { Dieta basal } \\
\text { Basal diet }\end{array}$} \\
\hline & 1 & 2 & 3 & 4 \\
\hline Lisina & 0,94 & 0,75 & 0,73 & 0,71 \\
\hline $\begin{array}{l}\text { Lysine } \\
\text { Metionina }\end{array}$ & 0,41 & 0,50 & 0,45 & 0,41 \\
\hline Methionine & & & & \\
\hline Cistina & 0,32 & 0,30 & 0,27 & 0,28 \\
\hline Cystine & & & & \\
\hline Met + Cis & 0,68 & 0,81 & 0,70 & 0,68 \\
\hline Met + cys & & & & \\
\hline Treonina & 0,76 & 0,68 & 0,61 & 0,57 \\
\hline Threonine & & & & \\
\hline Arginina & 1,26 & 1,08 & 1,01 & 0,96 \\
\hline Arginine & & & & \\
\hline Isoleucina & 0,91 & 0,74 & 0,78 & 0,72 \\
\hline Isoleucine & & & & \\
\hline Leucina & 2,26 & 2,04 & 2,13 & 1,91 \\
\hline Leucine & & & & \\
\hline Valina & 1,00 & 0,87 & 0,85 & 0,80 \\
\hline Valine & & & & \\
\hline Histidina & 0,52 & 0,47 & 0,46 & 0,42 \\
\hline Histidine & & & & \\
\hline Fenilalanina & 0,90 & - & 1,00 & 0,94 \\
\hline Phenilalanine & & & & \\
\hline
\end{tabular}

sentaram exigências de 1,183 e 1,188\% de lisina total, correspondendo a 1,104 e 1,108\% de lisina digestível, respectivamente, resultando em exigência média de $1,106 \%$ de lisina digestível. Estes resultados estão, em média, $8 \%$ acima dos obtidos por HAN e BAKER (1993), que encontraram exigência de 1,02\% de lisina digestível para máximo ganho de peso, tanto para machos quanto para fêmeas.

Já para a fase de 22 a 40 dias, considerando os dados de ganho de peso e conversão alimentar, a exigência de 1,03 e 0,993\% de lisina total de machos e fêmeas, correspondente à exigência de 0,925 e $0,891 \%$ de lisina digestível, está acima da obtida por HAN e BAKER (1994), que encontraram exigência de 0,85 e $0,78 \%$ de lisina digestível para máximo ganho de peso de machos e fêmeas, respectivamente. Para conversão alimentar mais eficiente, a exigência foi de 0,89 e $0,85 \%$ de lisina digestível para machos e fêmeas, respectivamente.

Considerando-se, conjuntamente, a exigência de lisina total para machos e fêmeas como 1,198; 1,125; 1,03; e $0,90 \%$, nas fases de 1 a 21,15 a 40, 22 a 40 e 42 a 48 dias de idade, respectivamente, determinadas previamente em quatro experimentos de desempenho realizados por (BARBOZA, 1998), as correspondentes exigências de lisina digestível serão 1,130; 1,053 ; 0,925; e 0,83\% (Tabela 5) para máximo desempenho das aves.

Ao converter estas exigências para o nível de $1000 \mathrm{kcal} \mathrm{EM} / \mathrm{kg}$ (Mcal/kg) de ração, resultam os valores de 0,$393 ; 0,352 ; 0,332 ;$ e $0,281 \%$ de lisina total

Tabela 5 - Exigência de lisina total e digestível nas dietas para as diferentes fases experimentais (\%)

Table 5 - Requirements of total and digestible lysine in the diets for the different experimental phases

\begin{tabular}{|c|c|c|c|}
\hline Item & Fase - dias & Phase - days & \\
\hline & 15 a $40^{(2)}$ & 22 a $40^{(3)}$ & \\
\hline
\end{tabular}

Lisina total

Total lysine

$\%$ na dieta

$\%$ in the diet

$1,198 \quad 1,125 \quad 1,03$

0,90

$\% /$ Mcal EM

0,393

0,352

0,332

0,281

$\% / M C a l M E$

Lisina digestível

Digestible lysine

$\begin{array}{lllll}\% \text { na dieta } & 1,130 & 1,053 & 0,925 & 0,830\end{array}$

$\%$ in the diet

$\begin{array}{lllll}\% / \text { Mcal EM } & 0,371 & 0,321 & 0,298 & 0,263\end{array}$

$\% / M C a l M E$

1 - Dieta basal (Basal diet) $3050 \mathrm{kcal} \mathrm{EM} / \mathrm{kg}$

2 - Dieta basal (Basal diet) $3200 \mathrm{kcal} \mathrm{EM} / \mathrm{kg}$.

3 - Dieta basal (Basal diet) $3100 \mathrm{kcal} \mathrm{EM/kg}$. 
1102 Rev. bras. zootec.

e 0,$371 ; 0,336 ; 0,307$; e $0,263 \%$ de lisina digestível verdadeira para as fases de 1 a 21,15 a 40,22 a 40 e 42 a 48 dias de idade, respectivamente.

Utilizando o modelo de regressão linear e considerando as exigências de lisina de cada fase, foram obtidas as equações $\hat{\mathrm{Y}}(\%$ lisina/Mcal $)=0,4335$ $0,003284 X\left(R^{2} 0,98\right)$ e $\hat{Y}(\%$ lisina/Mcal $)=0,41081$ $0,003213 X\left(R^{2} 0,96\right)$ para lisina total e digestível, respectivamente, sendo $\mathrm{X}$ a idade média das aves, em dias. Estas equações estão representadas na Figura 1, na qual se pode confirmar que as exigências nutricionais decrescem com a idade das aves, segundo HARTEL (1970), e o manual das marcas Ross e Hubbard. As equações possibilitam estimar as exigências das aves em qualquer programa de alimentação, pois são expressas em função da idade média das aves.

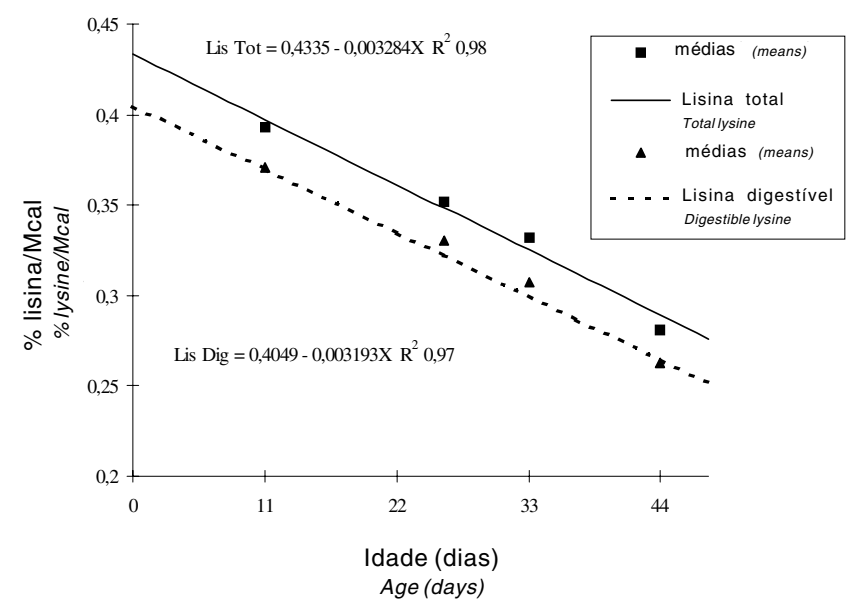

Figura 1 - Exigência de lisina total e digestível, em \%/Mcal, para frangos de corte, de acordo com a idade média, em dias.

Figure 1 - Requirement of total and digestible lysine, in \%/Mcal, for broiler chickens, according to the average age, in days.

\section{Conclusões}

Os coeficientes de digestibilidade verdadeira da lisina das dietas basais determinados com galos cecectomizados foram: 93,30; 93,58; 89,76; e 92,25\%. A exigência estimada de lisina digestível verdadeira foi de 1,$130 ; 1,053 ; 0,925 ;$ e $0,83 \%$, para as fases de 1 a 21 , 15 a 40,22 a 40 e 42 a 48 dias de idade, respectivamente.

Observou-se decréscimo linear da exigência de lisina, em relação à idade dos frangos de corte. Utilizando-se o modelo de regressão linear, foram obtidas as equações: $\hat{Y}(\%$ lisina/Mcal $)=0,4335$ $0,003284 \mathrm{X} \mathrm{r} \mathrm{r}^{2}=0,98$ e, $\hat{\mathrm{Y}}(\%$ lisina/Mcal $)=0,41081$ $0,003213 \mathrm{X} \mathrm{r}^{2}=0,96$, para lisina total e digestível, respectivamente, sendo $\mathrm{X}$ a idade média das aves, em dias.

\section{Referências Bibliográficas}

BARBOZA, W.A. Exigências nutricionais de lisina para duas marcas comerciais de frangos de corte. Viçosa, MG: UFV, 1998. 116p. Tese (Doutorado em Zootecnia) - Universidade Federal de Viçosa, 1998.

BILGILI, S.F., MORAN JR., E.T., ACAR, N. 1992. Strain cross response of heavy male broilers to dietary lysine in the finisher feed: live performance and further - processing yields. Poult. Sci., 71:850-858.

HAN, Y., BAKER, D.H. 1991. Lysine requirements of fast and - slow growing broiler chicks. Poult. Sci., 70:2108-2114.

HAN, Y., BAKER, D.H. 1992. Effects of heat stress, sex and body weight on responses of broiler chicks to dietary lysine. Poult. Sci., 71(1):37 (Suppl.).

HAN, Y., BAKER, D.H. 1993. Effects of sex, heat stress, body weight and genetic strain on the dietary lysine requirement of broiler chicks. Poult. Sci., 72:701-708.

HAN, Y., BAKER, D.H. 1994. Digestible lysine requirement of male and female broiler chicks during the period three to six weeks posthatching. Poult. Sci., 73:1739-1745.

HARTEL, H. 1970. Erganzungsbedarf con broilerrationen an methionin bei verwendung von sojashrot als alleiniger proteinquelle. Archiv fur Geflugelkunde, 34:173-181.

IZQUIERDO, O.A., PARSONS, C.M., BAKER, D.H. 1988. Bioavailability of lysine in L-lysine-HCl. J. Anim. Sci., 66(10):2590-2597.

PARSONS, C.M. 1991. Broiler feed formulation on a digestible amino-acid basis. In: LATIN AMERICAN POULTRY CONGRESS, 12, Quito, 1991. Anais... Quito, Equador, p.1-8.1991.

ROSTAGNO, H.S., FEATHERSTON, W. R. 1977. Estudo de métodos de determinação de disponibilidade de aminoácidos em pintos. R. Soc. Bras. Zootec, 6:64-75.

ROSTAGNO, H.S., SILVA, D.J., COSTA, P.M.A. et al. 1983. Composição de alimentos e exigências nutricionais de aves e suínos. Viçosa, UFV. 61p (Tabelas brasileiras).

SIBBALD, I.R. 1976. A bioassay for true metabolizable energy in feedingstuffs. Poult. Sci., 55:303-308.

SURISDIARTO, FARRELL, D.J. 1991. The relationship between dietary crude protein and dietary lysine requirement by broiler chicks on diets with and without the "ideal" amino acids balance. Poult. Sci., 70:830-836.

WALDROUP, P.W. 1991. Dietary nutrients allowances for chickens and turkeys. Feedstuffs, 63:29.

Recebido em: 03/08/1999

Aceito em: 04/02/2000 